\title{
Driving after Upper or Lower Extremity Orthopaedic Surgery
}

\author{
James S. MacKenzie ${ }^{1}$ Alexander M. Bitzer ${ }^{1} \quad$ Filippo Familiari $^{2} \quad$ Rocco Papalia $^{3} \quad$ Edward G. McFarland ${ }^{1}$ \\ ${ }^{1}$ Division of Shoulder Surgery, Department of Orthopaedic Surgery, \\ The Johns Hopkins University, Baltimore, Maryland, United States \\ 2 Department of Orthopaedics and Traumatology, Villa del Sole Clinic, \\ Catanzaro, Italy

\begin{abstract}
Address for correspondence Edward G. McFarland, MD, Division of Shoulder and Elbow Surgery, Department of Orthopaedic Surgery, The Johns Hopkins University, 10753 Falls Road, Pavilion II, Suite 215, Lutherville, MD 21093, United States (e-mail: emcfarl1@jhmi.edu).
\end{abstract}

${ }^{3}$ Department of Orthopaedic and Trauma Surgery, University of

Rome, Rome, Italy

Joints 2018;6:232-240.

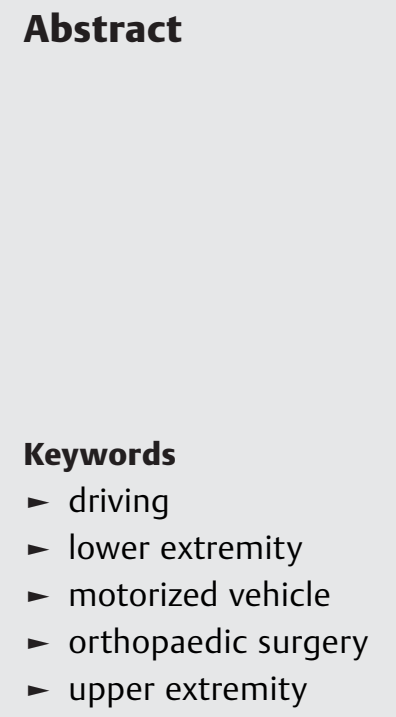

Orthopaedic procedures can affect patients' ability to perform activities of daily living, such as driving automobiles or other vehicles that require coordinated use of the upper and lower extremities. Many variables affect the time needed before a patient can drive competently after undergoing orthopaedic surgery to the extremities. These variables include whether the patient underwent upper or lower extremity surgery, the country in which the patient resides, whether the right or left lower extremity is involved, whether the dominant arm is involved, whether the extremity is in a cast or brace, whether the patient has adequate strength to control the steering wheel, and whether the patient is taking pain medication. The type and complexity of the procedure also influence the speed of return of driving ability. Few studies provide definitive data on driving ability after upper or lower extremity surgery. Patients should be counseled not to drive until they can control the steering wheel and the pedals competently and can drive well enough to prevent further harm to themselves or to others. This review discusses the limited recommendations in the literature regarding driving motorized vehicles after upper or lower extremity orthopaedic surgery.

\section{Introduction}

Driving is an integral component of functional living in modern society, and being able to drive safely is a key responsibility. However, driving, although frequently regarded as mundane or rudimentary, is quite complex. Driving requires precise coordination between the central nervous and musculoskeletal systems. Therefore, the decision about when a patient can drive safely after orthopaedic surgery is an important and difficult choice.

Despite the importance of this issue, no formal guidelines are available for patients or physicians to reference after orthopaedic surgery. ${ }^{1-3}$ The decision to resume driving involves numerous factors. ${ }^{4}$ Regardless of the multifactorial nature of the issue, medicolegal trends, including possible litigation, are commonly putting the responsibility for the decision solely on the patient. ${ }^{1,5,6}$ Some authors have advocated that physicians should not give detailed advice about when a patient can resume driving. ${ }^{7}$

Although there are no standard guidelines, the issue has been explored in the literature. Many authors have made recommendations about when it is appropriate to resume driving after undergoing a particular surgical procedure, but few studies of upper and lower extremity procedures are available to guide patients and clinicians. In this review, we summarize the literature on driving a motorized vehicle after undergoing upper or lower extremity surgery. Studies describing driving after spine surgery, pelvis surgery, or amputations were excluded. The purpose of this review is received

November 15, 2018

accepted after revision

December 26, 2018

published online

February 1, 2019
DOI https://doi.org/

$10.1055 / \mathrm{s}-0039-1678562$.

ISSN 2282-4324.
Copyright @ 2018 Georg Thieme Verlag

KG Stuttgart · New York
License terms

$\circledast(1) \Theta \circledast$ 
to help orthopaedic surgeons make informed recommendations regarding patients' driving after upper or lower extremity orthopaedic surgery.

\section{Lower Extremity}

\section{Lower Extremity and Driving}

Many variables affect the ability to drive after lower extremity surgery and the time required before patients can safely resume driving. The most important factors are the anatomic location of the surgery, the type of procedure performed, the extent and complexity of the surgery, and whether immobilization devices are needed. Country-specific traffic laws and standards must also be considered.

Most studies on driving focus on a patient's ability to react to an emergency when driving. ${ }^{3,8}$ Several studies have objectively measured this using driving simulators to determine brake reaction time (BRT), brake travel time (BTT), reaction time (RT; also called initial reaction time), movement time (MT; also called foot movement time), and total braking time (TBT; - Table 1). ${ }^{2,3,8-26}$ Unfortunately, these terms are often used interchangeably, making study comparisons difficult.

\section{Lower Extremity Immobilization}

Orthopaedic procedures performed on the lower extremity are treated postoperatively with a splint, brace, boot, or cast. The type of material used in the cast or splint can influence which activities the patient can perform. Similarly, the type of brace, the materials that constitute the brace, and the range of motion allowed by the brace influence the decision to allow a patient to drive a motorized vehicle.

Patients routinely ask their treating surgeons if it is safe for them to drive while immobilized, and many patients drive without surgeon approval. Kalamaras et $\mathrm{al}^{27}$ found that half of the 168 patients they surveyed during a 6-month period reported that they drove while wearing an upper extremity cast. In an anonymous survey of 118 patients, Kennedy et $\mathrm{al}^{28}$ determined that $15 \%$ of patients reported driving with a low-leg or short-arm cast/splint.

Using a driving simulator, Dammerer et al $^{10}$ investigated the effects of various types of right knee braces on BRT. They analyzed BRT in 64 patients wearing the following: no knee brace (control group), a hinged knee brace with various degrees of flexion restriction (0-30, 0-60, 0-90, and 2090 degrees), an offloading knee brace for unicompartmental arthritis, a knee sleeve, or an elastic knee bandage. They noted significantly longer BRT in all groups using the rangeof-motion-limiting knee brace, regardless of degree of flexion restriction. None of the other braces tested affected mean BRT compared with nonbraced controls. Waton et $\mathrm{al}^{25}$ examined the effect of long- and short-leg plaster casts, as well as hinged knee braces with varying degrees of flexion restriction on TBT in 23 people. The authors noted significant increases in TBT for above- and below-knee plaster casts. They also reported longer TBT for the hinged brace when it was in full extension, but, in contrast to Dammerer et $\mathrm{al}^{10}$ they found no significantly increased TBT with knee braces that allowed flexion to any degree.

The effects of boots, braces, and casts on driving ability after foot or ankle surgery have been reported by several authors. ${ }^{8,22,25}$ Murray et $\mathrm{al}^{22}$ investigated the effect of a pneumatic walking brace (Aircast Walking Boot, DJO Global, Vista, California, United States) or traditional walking cast on BRT compared with a control group wearing regular footwear. BRT increased by an average of 0.027 with the pneumatic walking brace and by more than 0.5 seconds with a walking cast (both, $p<0.01$ ). Orr et $\mathrm{al}^{8}$ examined BRT in patients with a traditional controlled ankle movement (CAM) walking boot or low-leg removable plaster cast and found significantly increased mean BRT in both groups. Overall, rigid immobilization of the right lower extremity prevents safe driving, and patients should be counseled accordingly.

\section{Lower Extremity Arthroplasty}

The number of hip and knee arthroplasty procedures in the U. S. and worldwide is projected to increase substantially in the coming decade. ${ }^{29}$ These procedures have a well-elucidated effect on driving ability; however, there is disagreement and inconsistency in the literature about how long patients need to recover to be able to drive safely (-Table 2). ${ }^{2,4,30}$ For example, the recommendations for right total knee arthroplasty (TKA) vary from 2 to 8 weeks. ${ }^{31,32}$ This creates a difficult clinical and medicolegal environment for orthopaedic surgeons and patients, and it is critical that surgeons performing these

Table 1 Definitions of commonly tested variables used to objectively measure driving ability after orthopaedic surgery

\begin{tabular}{|l|l|l|}
\hline Variable & Abbreviation & Definition \\
\hline Reaction time or initial reaction time & RT or IRT & Time from stimulus appearance to start of release of gas pedal \\
\hline Movement time or foot movement time & MT or FMT & $\begin{array}{l}\text { Time from start of release of gas pedal to initial contact with } \\
\text { brake pedal }\end{array}$ \\
\hline Brake travel time & BTT & $\begin{array}{l}\text { Time from initial contact with brake pedal to full depression of } \\
\text { brake pedal }\end{array}$ \\
\hline Brake reaction time & BRT & $\begin{array}{l}\text { RT }+ \text { MT (time from stimulus appearance to initial contact } \\
\text { with brake pedal) }\end{array}$ \\
\hline Total brake time & TBT & $\begin{array}{l}\text { RT }+ \text { MT + BTT (time from stimulus appearance to full } \\
\text { depression of brake pedal) }\end{array}$ \\
\hline
\end{tabular}


Table 2 Return-to-driving recommendations after THA, TKA, or UKA

\begin{tabular}{|c|c|c|c|c|c|}
\hline \multirow[t]{2}{*}{ First author } & \multirow[t]{2}{*}{ Year } & \multirow[t]{2}{*}{ Procedure } & \multirow[t]{2}{*}{ Evaluation method } & \multicolumn{2}{|c|}{ Recommendations/findings } \\
\hline & & & & Left side & Right side \\
\hline MacDonald $^{19}$ & 1988 & THA & BRT & 8 weeks & $\geq 8$ weeks \\
\hline Spalding $^{32}$ & 1994 & TKA & BRT & No delay & 8 weeks \\
\hline Pierson $^{24}$ & 2003 & TKA & BRT & $\geq 3$ weeks & $\geq 3$ weeks \\
\hline $\operatorname{Ganz}^{13}$ & 2003 & THA & BRT & 1 weeks & 4-6 weeks \\
\hline Berger $^{34}$ & 2004 & THA & Survey & 6 days & 6 days \\
\hline Marques $^{21}$ & 2008 & TKA & BRT & - & 30 days \\
\hline Marques $^{20}$ & 2008 & TKA & BRT & 10 days & \\
\hline Liebensteiner $^{36}$ & 2010 & TKA & BRT & 2 weeks & 2 weeks \\
\hline Abbas $^{33}$ & 2011 & THA & Survey & $84 \%$ at 6 weeks $^{\mathrm{a}}$ & $79 \%$ at 6 weeks $^{\mathrm{a}}$ \\
\hline Dalury $^{9}$ & 2011 & TKA & BRT & - & 4 weeks \\
\hline $\operatorname{Muh}^{60}$ & 2012 & TKA & Survey & \multicolumn{2}{|l|}{$1-3$ months } \\
\hline Jordan $^{17}$ & 2014 & THA & TBT & 8 days & 6 weeks \\
\hline Liebensteiner $^{18}$ & 2014 & UKA & BRT & No delay & 6 weeks \\
\hline Hernandez $^{35}$ & 2015 & THA & BRT & - & 2 weeks \\
\hline Dalury ${ }^{31}$ & 2018 & TKA & BRT & - & 2 weeks \\
\hline
\end{tabular}

Abbreviations: BRT, brake reaction time; THA, total hip arthroplasty; TKA, total knee arthroplasty; UKA, unicompartmental knee arthroplasty. ${ }^{a}$ Refers to the percentage of patients who reported driving at 6 weeks after surgery.

procedures understand the evidence regarding patient factors that may influence safe driving. ${ }^{1}$

MacDonald and Owen ${ }^{19}$ were among the first to study the effect of total hip arthroplasty (THA) on driving ability. They concluded that most patients could safely resume driving 8 weeks postoperatively, but that some patients require extended rehabilitation to return to baseline driving ability, which could take as long as 8 months. ${ }^{19}$ Most studies indicate that BRT returns to preoperative levels or that patients felt confident about driving between 4 and 8 weeks after THA. ${ }^{13,19,33}$ However, other studies suggest that patients may be able to drive sooner than 8 weeks. ${ }^{34,35}$ Berger et $\mathrm{al}^{34}$ advocated that patients could drive safely as soon as they stopped taking narcotic medication, which, in their study, was a mean of 6 days. The authors did not analyze objective data, such as BRT, but instead relied on patient surveys that asked patients when they thought they could safely start driving. ${ }^{34}$ Hernandez et $\mathrm{al}^{35}$ noted that 33 of 38 patients who underwent THA of the right hip had mean BRT of $0.576 \pm 0.137$ seconds by 2 weeks after surgery which was significantly better than the preoperative value of $0.635 \pm 0.160$ seconds $(p<0.029){ }^{35}$ Jordan et $\mathrm{al}^{17}$ examined the effect of left THA on TBT and found that patients returned to baseline levels 8 days after surgery.

TKA has been the subject of many biomechanical studies, especially to investigate the ability to perform an emergency stop. ${ }^{3}$ However, findings on a safe return-to-driving timeframe vary. BRT returned to normal preoperative levels by 6 weeks or less in several studies. ${ }^{9,21,24}$ Spalding et al ${ }^{32}$ used a simulator to measure BRT at $4,6,8$, and 10 weeks postoperatively and advocated that 8 weeks were needed before patients should resume driving. Conversely, in a study of BRT after TKA, Liebensteiner et $\mathrm{al}^{36}$ urged that patients should not be restricted from driving beyond 2 weeks postoperatively, regardless of whether the procedure was performed on the left or right extremity. The same group found that BRT did not return to preoperative levels until 6 weeks after right unicompartmental arthroplasty and recommended that patients not drive until this point. ${ }^{18}$ Marques et al ${ }^{20}$ prospectively analyzed BRT in patients who underwent left TKA. They found that patients had slightly decreased RT in simple and complex braking tasks, at 10 days postoperatively, but these changes were nonsignificant. The authors concluded that patients who undergo left TKA can drive safely using an automatic transmission at 10 days postoperatively.

Systematic reviews have generated some recommendations regarding returning to driving after right THA and $\mathrm{TKA}^{2,4}$ but no study, to our knowledge, has recommended a timeline that can be used as a definitive guideline for physicians or regulatory bodies. Some publications have suggested that there should be official guidelines from local or national government agencies to absolve physicians from potential liability for allowing patients to drive when they were not capable or for the ability of the patient to make the decision for themselves. ${ }^{1,2,4,5,7}$

\section{Knee Arthroscopy}

Like arthroplasty, rates of arthroscopic knee procedures in the United States and worldwide are increasing. In 2006, nearly 1 million arthroscopic knee procedures were performed in the United States, and more than 127,000 of those were anterior cruciate ligament $(\mathrm{ACL})$ reconstructions. ${ }^{37}$ 
More than $99 \%$ of arthroscopic procedures are performed in the outpatient setting, which presents a unique challenge to orthopaedic surgeons regarding counseling patients about when it is safe to drive again. Despite the number of arthroscopic procedures being performed, Argintar et $\mathrm{al}^{38}$ found that most surgeons (57\%) discussed postoperative driving instructions during preoperative consultation with only half of their patients or less.

The type of arthroscopic procedure is perhaps the most important factor to consider when deciding when a patient can safely drive. ${ }^{38}$ Simple procedures, such as diagnostic arthroscopy, partial meniscectomy, chondroplasty, or debridement typically allow an expeditious return to safe driving. Argintar et $\mathrm{al}^{38}$ suggested that patients undergoing such procedures may resume driving 1 week postoperatively if they are no longer taking narcotic medications. Hau et $\mathrm{al}^{16}$ compared TBT in 30 patients who underwent partial meniscectomy, chondroplasty, or diagnostic arthroscopy with that of preoperative controls. At 1 week after surgery, mean TBT increased to 920 milliseconds from a preoperative value of 736 milliseconds. This represents an increased stopping distance of $5.2 \mathrm{~m}$ in a car traveling at $100 \mathrm{~km} / \mathrm{h}$. By 4 weeks postoperatively, mean TBT was 685 milliseconds, which was better than the preoperative assessment. Therefore, they recommended that patients wait at least 1 week to resume driving after right knee arthroscopy. ${ }^{16}$

Compared with simpler arthroscopic procedures, ACL reconstruction typically requires a longer rehabilitation and recovery time; many patients require more than 9 months before resuming sport. ${ }^{39}$ Perhaps it is not surprising that studies examining return to driving after ACL reconstruction support a 4- to 6-week recovery time (-Table 3). 2,4,14,23 Gotlin et $\mathrm{al}^{14}$ and Nguyen et $\mathrm{al}^{23}$ examined BRT after right ACL reconstruction and found that BRT returned to preoperative levels by 6 weeks postoperatively. Wasserman et $\mathrm{al}^{40}$ examined the effects of three types of ACL grafts on BRT at 1, 3, and 6 weeks postoperatively, compared with nonoperative patients. The authors found that patients who underwent ACL reconstruction with an allograft (tibialis anterior) regained normal BRT by 3 weeks, and patients treated with either autograft (hamstring or bonepatellar tendon-bone) regained normal BRT by 6 weeks postoperatively. ${ }^{40}$

\section{Lower Extremity Trauma}

Traumatic injuries to the lower extremity vary greatly in severity. Few studies have addressed return to driving after lower extremity trauma, and the decision must be tailored to the specific injury and degree of impairment ( - Table 4). Egol et $\mathrm{al}^{12}$ examined the effect on BRT of an operatively treated right ankle fracture. In their study, 31 patients who underwent ankle open reduction and internal fixation were tested on a driving simulator at 6,9 , and 12 weeks postoperatively, and their results were compared with those of healthy controls. The increased BRT represented a nonsignificant increased stopping distance in a car traveling at $97 \mathrm{~km} / \mathrm{h}$ of $6.7 \mathrm{~m}$ at 6 weeks and $2.4 \mathrm{~m}$ at 9 weeks postoperatively. The authors concluded that BRT returned to baseline values by 9 weeks postoperatively. ${ }^{12}$

Egol et $\mathrm{al}^{11}$ studied the effect on BTT of various types of articular and long-bone fractures. Patients were categorized into the following three groups: healthy controls $(n=12)$, long-bone fractures ( $n=22: 9$ femur, 13 tibia), and articular fractures $(n=35$ : 12 calcaneus, 12 plateau, 7 acetabulum, and 4 pilon). The authors found that BTT was significantly increased in all groups until 6 weeks after resuming full weight bearing. Thereafter, most patients' BTT had returned to baseline, allowing them to drive safely.

A recent study by Ho et $\mathrm{al}^{41}$ examined patients' ability to drive safely after surgical treatment of right ankle fractures. The authors assessed this by using BRT, the short musculoskeletal functional assessment, and an on-road driving test with a driving instructor if they met minimum criteria in simulated BRT and short musculoskeletal functional

Table 3 Return-to-driving recommendations after arthroscopic knee surgery

\begin{tabular}{|c|c|c|c|c|c|}
\hline \multirow[t]{2}{*}{ First author } & \multirow[t]{2}{*}{ Year } & \multirow[t]{2}{*}{ Procedure } & \multirow{2}{*}{$\begin{array}{l}\text { Evaluation } \\
\text { method }\end{array}$} & \multicolumn{2}{|c|}{ Recommendations/findings } \\
\hline & & & & Left knee & Right knee \\
\hline Nguyen $^{23}$ & 2000 & $\begin{array}{l}\text { Anterior cruciate ligament } \\
\text { reconstruction }\end{array}$ & BRT & 2 weeks & 6 weeks \\
\hline Gotlin $^{14}$ & 2000 & $\begin{array}{l}\text { Anterior cruciate ligament } \\
\text { reconstruction }\end{array}$ & BRT & & 4-6 weeks \\
\hline $\mathrm{Hau}^{16}$ & 2000 & $\begin{array}{l}\text { Partial meniscectomy, chondroplasty, } \\
\text { diagnostic scopes }\end{array}$ & BRT & & $\geq 1$ week \\
\hline Lewis $^{77}$ & 2011 & $\begin{array}{l}\text { Partial meniscectomy, chondroplasty, } \\
\text { diagnostic scopes }\end{array}$ & Survey & & 1 day to $\geq 3$ weeks \\
\hline Argintar $^{38}$ & 2013 & $\begin{array}{l}\text { Partial meniscectomy, chondroplasty, } \\
\text { debridement }\end{array}$ & Survey & & 1 week \\
\hline Wasserman $^{40}$ & 2017 & $\begin{array}{l}\text { Anterior cruciate ligament } \\
\text { reconstruction }\end{array}$ & BRT & & $\begin{array}{l}3 \text { weeks after tibialis anterior } \\
\text { allograft; } 6 \text { weeks after ham- } \\
\text { string and BPTB autograft }\end{array}$ \\
\hline
\end{tabular}

Abbreviations: BPTB, bone-patellar tendon-bone; BRT, brake reaction time. 
Table 4 Return-to-driving recommendations after trauma to the right lower extremity

\begin{tabular}{|l|l|l|l|l|}
\hline First author & Year & Procedure & $\begin{array}{l}\text { Evaluation } \\
\text { method }\end{array}$ & Recommendations/findings \\
\hline Egol $^{12}$ & 2003 & Ankle ORIF & BRT & 9 weeks \\
\hline Egol $^{11}$ & 2008 & Tibia or femur intramedullary nailing & BRT & $\begin{array}{l}12 \text { weeks (6 weeks after full weight } \\
\text { bearing) }\end{array}$ \\
\hline Egol $^{11}$ & 2008 & $\begin{array}{l}\text { Acetabulum, tibial plateau, pilon, } \\
\text { calcaneus ORIF }\end{array}$ & BRT & $\begin{array}{l}18 \text { weeks (6 weeks after full weight } \\
\text { bearing) }\end{array}$ \\
\hline Yousri & 2015 & $\begin{array}{l}\text { Operative and nonoperative ankle } \\
\text { fractures }\end{array}$ & BRT & 8 days after cast removal \\
\hline $\mathrm{Ho}^{41}$ & 2018 & Ankle ORIF & BRT and SMFA & 6 weeks \\
\hline
\end{tabular}

Abbreviations: BRT, brake reaction time; ORIF, open reduction and internal fixation; SMFA, short musculoskeletal functional assessment.

assessment testing. Compared with the findings of Egol et $\mathrm{al}^{12}$ they found that patients can safely resume driving at 6 weeks postoperatively, even before weight bearing is initiated.

\section{Upper Extremity}

\section{Upper Extremity and Driving}

There are no specific guidelines for safe return to driving after immobilization or surgery for injuries or chronic conditions of the upper extremity. Whereas BRT is commonly used to gauge when it is safe to resume driving after lower extremity surgery, no similar metric exists for the upper extremity. Thus, orthopaedic surgeons rely on their own judgment or anecdotal experience rather than evidencebased clinical guidelines. ${ }^{1}$ This creates varying opinions on and protocols for determining when it is safe to resume driving (- Table 5). ${ }^{42-46}$

When considering surgeries to the upper extremity, the specific area of involvement and the type of condition being treated influence when it is safe to resume driving. Each joint in the upper extremity contributes to the motion and strength needed to operate the gear shift and the steering wheel. In a study by Liu et $\mathrm{al}^{47}$ patients used a driving simulator while undergoing electromyography, showing that several shoulder muscles are essential in clockwise and counterclockwise steering maneuvers. The authors found that only small degrees of motion at the shoulder could produce large changes in steering direction. Rawal et $\mathrm{al}^{48}$ performed a study using motion analysis of joint biomechanics during driving and determined that shoulder flexion and rotation, as well as forearm pronation and supination, were the most important factors in safe driving. The mean ranges of shoulder motion needed for hazard avoidance were 20 to 48 degrees of shoulder flexion and 2.1 to 26 degrees of internal rotation. The mean ranges of forearm motion needed for hazard avoidance were 7.2 degrees of supination to 62 degrees of pronation. ${ }^{30}$

\section{Upper Extremity Immobilization}

After upper extremity surgery, immobilization protects the limb or joint from excessive stress. Unfortunately, this can lead to prolonged loss of motion, loss of function, and impaired ability to drive safely. Immobilization devices used in the upper extremity include casts, splints, braces, and slings. The appropriate application of these devices is important to gain maximum benefit from surgery. ${ }^{49}$

The shoulder has a large range of motion and thus is typically able to compensate when performing tasks that

Table 5 Return-to-driving recommendations after upper extremity surgery

\begin{tabular}{|l|l|l|l|l|}
\hline First Author & Year & Procedure & Evaluation method & Recommendations/findings \\
\hline Acharya $^{76}$ & 2005 & CTR & Survey & $\begin{array}{l}\text { Resume driving safely at } 9 \text { days; } \\
\text { patients with bilateral CTRs took } \\
\text { longer to resume driving }\end{array}$ \\
\hline Hammert $^{75}$ & 2012 & $\begin{array}{l}\text { Outpatient hand soft } \\
\text { tissue surgery }\end{array}$ & Survey & $\begin{array}{l}\text { 50\% of patients drove immediately } \\
\text { after surgery; remaining drove } \\
\text { within } 1 \text { week }\end{array}$ \\
\hline Hasan $^{45}$ & 2016 & TSA and rTSA & Driving simulator & Recommend 6-12 weeks \\
\hline Hasan $^{44}$ & 2016 & $\begin{array}{l}\text { Arthroscopic RCR and } \\
\text { labral repair }\end{array}$ & Driving simulator & $\begin{array}{l}\text { Return to preoperative driving } \\
\text { function at 12 weeks }\end{array}$ \\
\hline Jones $^{53}$ & 2017 & Distal radius ORIF & $\begin{array}{l}\text { Closed course driving } \\
\text { examination }\end{array}$ & 3 weeks \\
\hline
\end{tabular}

Abbreviations: CTR, carpal tunnel release; ORIF, open reduction and internal fixation; RCR, rotator cuff repair; rTSA, reverse total shoulder arthroplasty; TSA, total shoulder arthroplasty. 
require upper extremity coordination and movement during periods of immobilization of the upper extremity. Flexion and rotation are important for steering, and limiting these motions via immobilization impairs driving ability. ${ }^{47}$ Hasan et $\mathrm{al}^{50}$ found that immobilization of the shoulder in a sling decreases driving performance and the ability to perform evasive maneuvers during hazardous conditions. Patients should be informed that driving with an immobilized arm can result in further injury to themselves or others.

Immobilization from the forearm to above the elbow, such as with a long-arm cast, significantly inhibits the ability to drive safely ${ }^{27,51,52}$ by diminishing pronation and supination (more so than elbow flexion and extension ${ }^{48}$ ). Therefore, few patients drive with above-the-elbow immobilization. However, most patients who drive with upper extremity immobilization are those in short-arm casts with the elbow free. ${ }^{51}$ This discrepancy is caused by the fact that short-arm casts and splints are the most common type of upper extremity immobilization and have been deemed safe to use while driving. ${ }^{43}$

Wrist immobilization is considered to allow safe driving but only when grip strength is preserved. ${ }^{43}$ Devices that limit grip strength, such as thumb spica casts, have been shown to increase perceived driving difficulty. Jones et $\mathrm{al}^{53}$ showed that patients wearing a thumb spica cast made more mistakes during test drives on a simulated driving circuit. ${ }^{43}$ The influence of laterality is unclear because studies show mixed results when determining whether immobilization of the right versus left is more impairing. ${ }^{42,43}$ Finally, finger immobilization should not affect one's ability to drive if grip strength is preserved.

\section{Shoulder Arthroplasty}

Anatomic and reverse total shoulder arthroplasty improve pain and functional outcomes in patients with various degenerative shoulder conditions. ${ }^{54,55}$ The number of shoulder arthroplasty continues to increase given the demands of an aging population, advances in shoulderspecific arthroplasty training, and improvements in implant technology and availability. ${ }^{56}$ The mean age of patients undergoing shoulder arthroplasty is approximately 70 years, which is an age at which many adults are still driving. ${ }^{57}$

It is considered unsafe to drive during the immediate period after shoulder arthroplasty when most patients' shoulders are immobilized in a brace or sling and patients are often taking narcotic medicine for pain. ${ }^{58,59}$ There is less agreement about the safety of driving after shoulder immobilization and narcotic medicine have been discontinued. Using a driving simulator, Hasan et $\mathrm{al}^{44}$ tested 30 patients after shoulder arthroplasty and found that driving function was at least equivalent to preoperative values at 6 weeks postoperatively. By 12 weeks, driving ability was better than preoperative values because of reduced pain, increased range of motion, and better shoulder function. The authors concluded that patients could drive safely between 6 and 12 weeks after shoulder arthroplasty. ${ }^{44}$ Muh et $\mathrm{al}^{60}$ found that 12 of 31 of patients had resumed driving within 1 month after total shoulder arthroplasty, whereas 29 of 31 resumed driving within 3 months after surgery.

\section{Shoulder Arthroscopy}

Similar to shoulder arthroplasty, the number of arthroscopic shoulder surgeries is also increasing, ${ }^{61}$ including rotator cuff repairs, labral repair, biceps tenodesis, and subacromial decompression. ${ }^{62-66}$ Patients may require 1 day to 4 months to resume driving after rotator cuff surgery. ${ }^{67}$ Meanwhile, patients who undergo subacromial decompression, without rotator cuff repair, return to driving within a mean of 1 month postoperatively. ${ }^{68}$ One study found impaired driving performance for at least 6 weeks after arthroscopic rotator cuff or labral repair when using a validated driving simulator; driving ability did not return to preoperative levels until approximately 12 weeks postoperatively. ${ }^{45}$

Decreased driving performance after arthroscopic shoulder surgery is caused by temporary muscle weakness, pain, and stiffness. Patient surveys after arthroscopic shoulder surgery show that pain and weakness are the primary factors that make patients feel unsafe to drive because of increased difficulty in steering. ${ }^{67}$ One prospective study reported that approximately half of patients (81 of 166) who underwent arthroscopic rotator cuff repair had activity-limiting stiffness and weakness at 6 weeks postoperatively. ${ }^{69}$ Another prospective study found that $43 \%$ of patients (19 of 44) who underwent arthroscopic rotator cuff repair had pain for at least 6 weeks after surgery. ${ }^{70}$

\section{Hand and Wrist Surgery}

Surgery on the hand or wrist can affect driving in several ways. Patients may experience loss of grip strength because of immobilization and pain and loss of motion and function associated with the procedure itself. Although a large portion of the wrist's total arc of motion is used while driving, this high degree of wrist motion correlates to only small changes in steering wheel position. ${ }^{48}$ Therefore, the wrist's contribution to steering wheel maneuvering is minimal.

The incidence and operative treatment of distal radius fractures and carpal tunnel syndrome have increased during the last several decades, ${ }^{71-73}$ making them among the most common surgeries performed on the hand and wrist. ${ }^{73,74}$ Jones et $\mathrm{al}^{53}$ conducted a prospective trial with 23 patients and determined that most patients who underwent open reduction and internal fixation via volar plating of the distal radius could drive safely at 3 weeks postoperatively. The authors concluded that postoperative pain was a major factor that limited safe driving.

Minimally invasive surgeries of the hand and wrist appear to have less deleterious effects on driving, and, as a result, the return-to-driving time is typically less than that associated with other upper extremity surgeries. Hammert et $\mathrm{al}^{75}$ found that half of patients (69 of 139) who underwent minimally invasive procedures, of which most involved only soft tissue and were performed on an outpatient basis, were able to drive immediately after surgery. Included were carpal tunnel releases, annular one pulley releases, mucous cyst excisions, ganglion cyst excisions, first dorsal compartment releases, foreign body removals, and amputations. In a prospective study, Acharya et $\mathrm{al}^{76}$ found that approximately half of 75 patients who 
underwent open carpal tunnel release had resumed driving 9 days postoperatively. Notably, patients who underwent simultaneous bilateral carpal tunnel release took significantly longer to resume driving compared with those who underwent unilateral carpal tunnel release.

Surgeries and injuries to the upper extremity are common, and treatment modalities can affect one's ability to drive safely. Research on the topic suggests that injuries involving the shoulder and elbow appear to limit driving more so than those involving the midforearm, wrist, and hand. Additionally, it takes longer to resume safe driving after shoulder surgery compared with other upper extremity surgeries. The establishment of return-to-driving guidelines would be helpful for surgeons and patients and should be based on current and future studies.

\section{Conclusion}

Many factors must be considered when counseling patients about when to resume driving after orthopaedic surgery. These factors include the following: whether surgery was performed on the upper or lower extremity, use of narcotic medications, whether surgery was performed on the dominant arm or braking leg, the type of surgical procedure, whether the limb is immobilized or in a brace, the amount of pain the patient is experiencing, the patient's range of motion and muscle strength, and the ability of the patient to control the vehicle. Studies have provided some data on the length of time it takes to recover from orthopaedic surgery to a degree that allows safe driving. Ultimately, this decision requires consideration of all of these variables and an informed discussion with the patient. The decision to resume driving should be made on a case-by-case basis.

\section{Funding}

None.

\section{Conflict of Interest}

None declared.

\section{References}

1 Chen V, Chacko AT, Costello FV, Desrosiers N, Appleton P, Rodriguez EK. Driving after musculoskeletal injury. Addressing patient and surgeon concerns in an urban orthopaedic practice. J Bone Joint Surg Am 2008;90(12):2791-2797

2 DiSilvestro KJ, Santoro AJ, Tjoumakaris FP, Levicoff EA, Freedman $\mathrm{KB}$. When can I drive after orthopaedic surgery? A systematic review. Clin Orthop Relat Res 2016;474(12):2557-2570

3 Marecek GS, Schafer MF. Driving after orthopaedic surgery. J Am Acad Orthop Surg 2013;21(11):696-706

4 Goodwin D, Baecher N, Pitta M, Letzelter J, Marcel J, Argintar E. Driving after orthopedic surgery. Orthopedics 2013;36(06): 469-474

5 Nuñez VA, Giddins GE. 'Doctor, when can I drive?': an update on the medico-legal aspects of driving following an injury or operation Injury 2004;35(09):888-890

6 Murphy SF, Martin-Smith JD, Martin-Smith W, O'Broin E, Clover AJP. When do we think it is safe to drive after hand surgery? Current practice and legal perspective. Ir Med J 2016;109(10): 484
7 Giddins GE, Hammerton A. "Doctor, when can I drive?": a medical and legal view of the implications of advice on driving after injury or operation Injury 1996;27(07):495-497

8 Orr J, Dowd T, Rush JK, Hsu J, Ficke J, Kirk K. The effect of immobilization devices and left-foot adapter on brake-response time. J Bone Joint Surg Am 2010;92(18):2871-2877

9 Dalury DF, Tucker KK, Kelley TC. When can I drive?: brake response times after contemporary total knee arthroplasty Clin Orthop Relat Res 2011;469(01):82-86

10 Dammerer D, Giesinger JM, Biedermann R, Haid C, Krismer M, Liebensteiner $M$. Effect of knee brace type on braking response time during automobile driving. Arthroscopy 2015;31(03): 404-409

11 Egol KA, Sheikhazadeh A, Koval KJ. Braking function after complex lower extremity trauma. J Trauma 2008;65(06):1435-1438

12 Egol KA, Sheikhazadeh A, Mogatederi S, Barnett A, Koval KJ. Lower-extremity function for driving an automobile after operative treatment of ankle fracture. J Bone Joint Surg Am 2003;85-A (07):1185-1189

13 Ganz SB, Levin AZ, Peterson MG, Ranawat CS. Improvement in driving reaction time after total hip arthroplasty. Clin Orthop Relat Res 2003;(413):192-200

14 Gotlin RS, Sherman AL, Sierra N, Kelly MA, Pappas Z, Scott WN. Measurement of brake response time after right anterior cruciate ligament reconstruction. Arch Phys Med Rehabil 2000;81(02): 201-204

15 Hartman J, Thornley P, Oreskovich S, Adili A, Bedi A, Khan M. Braking time following total knee arthroplasty: a systematic review. J Arthroplasty 2018;33(01):284-290

16 Hau R, Csongvay S, Bartlett J. Driving reaction time after right knee arthroscopy. Knee Surg Sports Traumatol Arthrosc 2000;8 (02):89-92

17 Jordan M, Hofmann UK, Grünwald J, et al. Influence of left- and right-side total hip arthroplasty on the ability to perform an emergency stop while driving a car. Arch Phys Med Rehabil 2014; 95(09):1702-1709

18 Liebensteiner MC, Rochau H, Renz P, et al. Brake response time returns to the pre-surgical level 6 weeks after unicompartmental knee arthroplasty. Knee Surg Sports Traumatol Arthrosc 2014;22 (08):1926-1931

19 MacDonald W, Owen JW. The effect of total hip replacement on driving reactions. J Bone Joint Surg Br 1988;70(02):202-205

20 Marques CJ, Barreiros J, Cabri J, Carita AI, Friesecke C, Loehr JF. Does the brake response time of the right leg change after left total knee arthroplasty? A prospective study. Knee 2008;15(04): 295-298

21 Marques CJ, Cabri J, Barreiros J, Carita AI, Friesecke C, Loehr JF. The effects of task complexity on brake response time before and after primary right total knee arthroplasty. Arch Phys Med Rehabil 2008;89(05):851-855

22 Murray JC, Tremblay MA, Corriveau H, Hamel M, Cabana F. Effects of right lower limb orthopedic immobilization on braking function: an on-the-road experimental study with healthy volunteers. J Foot Ankle Surg 2015;54(04):554-558

23 Nguyen T, Hau R, Bartlett J. Driving reaction time before and after anterior cruciate ligament reconstruction. Knee Surg Sports Traumatol Arthrosc 2000;8(04):226-230

24 Pierson JL, Earles DR, Wood K. Brake response time after total knee arthroplasty: when is it safe for patients to drive? J Arthroplasty 2003;18(07):840-843

25 Waton A, Kakwani R, Cooke NJ, et al. Immobilisation of the knee and ankle and its impact on drivers' braking times: a driving simulator study. J Bone Joint Surg Br 2011;93(07):928-931

26 Yousri T, Jackson M. Ankle fractures: when can I drive, doctor? A simulation study. Injury 2015;46(02):399-404

27 Kalamaras MA, Rando A, Pitchford DG. Driving plastered: who does it, is it safe and what to tell patients. ANZ J Surg 2006;76(06): 439-441 
28 Kennedy MT, Roche S, Lenehan B, et al. Driving plastered: driving habits of orthopaedic outpatients and the medico-legal implications. Eur J Orthop Surg Traumatol 2006;16:228-230

29 Sloan M, Sheth NP. Projected volume of primary and revision total joint arthroplasty in the United States, 2030-2060. Presented at the American Academy of Orthopaedic Surgeons 2018 Annual Meeting (New Orleans, LA), March 6-10, 2018. Available at: http://submissions.mirasmart.com/Verify/AAOS2018/Submission/out/AAOS2018-002064.PDF. Accessed January 25, 2019

30 MacLeod K, Lingham A, Chatha $\mathrm{H}$, et al. "When can I return to driving?": a review of the current literature on returning to driving after lower limb injury or arthroplasty Bone Joint J 2013;95-B(03):290-294

31 Dalury DF, Chapman DM. Right TKR patients treated with enhanced pain and rehabilitation protocols can drive at 2 weeks. J Knee Surg 2018

32 Spalding TJW, Kiss J, Kyberd P, Turner-Smith A, Simpson AH. Driver reaction times after total knee replacement. J Bone Joint Surg $\mathrm{Br}$ 1994;76(05):754-756

33 Abbas G, Waheed A. Resumption of car driving after total hip replacement. J Orthop Surg (Hong Kong) 2011;19(01):54-56

34 Berger RA, Jacobs JJ, Meneghini RM, Della Valle C, Paprosky W, Rosenberg AG. Rapid rehabilitation and recovery with minimally invasive total hip arthroplasty. Clin Orthop Relat Res 2004;(429): 239-247

35 Hernandez VH, Ong A, Orozco F, Madden AM, Post Z. When is it safe for patients to drive after right total hip arthroplasty? J Arthroplasty 2015;30(04):627-630

36 Liebensteiner MC, Kern M, Haid C, Kobel C, Niederseer D, Krismer M. Brake response time before and after total knee arthroplasty: a prospective cohort study. BMC Musculoskelet Disord 2010; 11:267

37 Kim S, Bosque J, Meehan JP, Jamali A, Marder R. Increase in outpatient knee arthroscopy in the United States: a comparison of National Surveys of Ambulatory Surgery, 1996 and 2006. J Bone Joint Surg Am 2011;93(11):994-1000

38 Argintar E, Williams A, Kaplan J, et al. Recommendations for driving after right knee arthroscopy. Orthopedics 2013;36(05): 659-665

39 DeFroda SF, Hiller K, Cruz AI. Pediatric anterior cruciate ligament rehabilitation: a review. R I Med J (2013) 2017;100(11):26-30

40 Wasserman BR, Singh BC, Kaplan DJ, et al. Braking reaction time after right-knee anterior cruciate ligament reconstruction: a comparison of 3 grafts. Arthroscopy 2017;33(01):173-180

41 Ho SWL, Yam M, Chan ML, Kwek EBK. Return to car driving is safe 6 weeks after operative treatment of right ankle fractures. Arch Orthop Trauma Surg 2018;138(12):1691-1697

42 Blair S, Chaudhri O, Gregori A. Doctor, can I drive with this plaster? An evidence based response. Injury 2002;33(01):55-56

43 Gregory JJ, Stephens AN, Steele NA, Groeger JA. Effects of upperlimb immobilisation on driving safety. Injury 2009;40(03): 253-256

44 Hasan S, McGee A, Garofolo G, et al. Changes in driving performance following shoulder arthroplasty. J Bone Joint Surg Am 2016;98(17):1471-1477

45 Hasan S, McGee A, Weinberg M, et al. Change in driving performance following arthroscopic shoulder surgery. Int J Sports Med 2016;37(09):748-753

46 Rees JL, Sharp RJ. Safety to drive after common limb fractures. Injury 2002;33(01):51-54

47 Liu Y, Ji X, Ryouhei H, et al. Function of shoulder muscles of driver in vehicle steering maneuver. Sci China Technol Sci 2012;55(12): 3445-3454

48 Rawal A, Chehata A, Horberry T, Shumack M, Chen C, Bonato L. Defining the upper extremity range of motion for safe automobile driving. Clin Biomech (Bristol, Avon) 2018;54:78-85

49 McFarland EG, Curl LA, Urquhart MW, Kellam K. The sling. Shoulder immobilization devices. Orthop Nurs 1997;16(04):17-20
50 Hasan S, Chay E, Atanda A, McGee AW Jr, Jazrawi LM, Zuckerman JD. The effect of shoulder immobilization on driving performance. J Shoulder Elbow Surg 2015;24(02):273-279

51 Chong PY, Koehler EA, Shyr Y, et al. Driving with an arm immobilized in a splint: a randomized higher-order crossover trial. J Bone Joint Surg Am 2010;92(13):2263-2269

52 Stevenson HL, Peterson N, Talbot C, Dalal S, Watts AC, Trail IA. An objective assessment of safety to drive in an upper limb cast. J Hand Surg Eur Vol 2013;38(03):321-324

53 Jones EM, Barrow AE, Skordas NJ, Green DP, Cho MS. The effects of below-elbow immobilization on driving performance. Injury 2017;48(02):327-331

54 Bryant D, Litchfield R, Sandow M, Gartsman GM, Guyatt G, Kirkley A. A comparison of pain, strength, range of motion, and functional outcomes after hemiarthroplasty and total shoulder arthroplasty in patients with osteoarthritis of the shoulder. A systematic review and meta-analysis. J Bone Joint Surg Am 2005;87(09): 1947-1956

55 Nolan BM, Ankerson E, Wiater JM. Reverse total shoulder arthroplasty improves function in cuff tear arthropathy. Clin Orthop Relat Res 2011;469(09):2476-2482

56 Westermann RW, Pugely AJ, Martin CT, Gao Y, Wolf BR, Hettrich CM. Reverse shoulder arthroplasty in the United States: a comparison of national volume, patient demographics, complications, and surgical indications. Iowa Orthop J 2015;35:1-7

57 U.S. Department of Transportation. Federal Highway Administration. Licensed drivers by age and sex (in thousands). Available at: https://www.fhwa.dot.gov/ohim/onh00/bar7.htm. Accessed October 26, 2018

58 Leroy AA, Pharm D, Morse ML. Multiple medications and vehicle crashes: analysis of databases. Available at: https://www.nhtsa. gov/DOT/NHTSA/Traffic\%20Injury\%20Control/Articles/Associated\% 20Files/810858.pdf. Accessed October 26, 2008

59 Meuleners LB, Duke J, Lee AH, Palamara P, Hildebrand J, Ng JQ. Psychoactive medications and crash involvement requiring hospitalization for older drivers: a population-based study. J Am Geriatr Soc 2011;59(09):1575-1580

60 Muh SJ, Shishani Y, Streit JJ, et al. The impact of joint replacement on driver function and safety. Open J Orthop 2012;2:121-125

61 Colvin AC, Egorova N, Harrison AK, Moskowitz A, Flatow EL. National trends in rotator cuff repair. J Bone Joint Surg Am 2012;94(03):227-233

62 Godinho GG, França FO, Freitas JM, Pinto LB, Simionatto CL, Viana Filho PP. Functional outcome after arthroscopic repair of triple shoulder instability. Rev Bras Ortop 2017;52(02):182-188

63 Klintberg IH, Svantesson U, Karlsson J. Long-term patient satisfaction and functional outcome 8-11 years after subacromial decompression. Knee Surg Sports Traumatol Arthrosc 2010;18(03): 394-403

64 Lee E, Bishop JY, Braman JP, Langford J, Gelber J, Flatow EL. Outcomes after arthroscopic rotator cuff repairs. J Shoulder Elbow Surg 2007;16(01):1-5

65 Nord KD, Smith GB, Mauck BM. Arthroscopic biceps tenodesis using suture anchors through the subclavian portal. Arthroscopy 2005;21(02):248-252

66 Saper MG, Milchteim C, Zondervan RL, Andrews JR, Ostrander RV III. Outcomes after arthroscopic bankart repair in adolescent athletes participating in collision and contact sports. Orthop J Sports Med 2017;5(03):2325967117697950

67 Gholson JJ, Lin A, McGlaston T, DeAngelis J, Ramappa A. Return to driving after arthroscopic rotator cuff repair: patient-reported safety and maneuverability. J Surg Orthop Adv 2015;24(02): 125-129

68 McClelland D, Paxinos A, Dodenhoff RM. Rate of return to work and driving following arthroscopic subacromial decompression. ANZ J Surg 2005;75(09):747-749

69 Peters KS, McCallum S, Briggs L, Murrell GA. A comparison of outcomes after arthroscopic repair of partial versus small or 
240 Driving after Orthopaedic Surgery MacKenzie et al.

medium-sized full-thickness rotator cuff tears. J Bone Joint Surg Am 2012;94(12):1078-1085

70 Williams G Jr, Kraeutler MJ,Zmistowski B, Fenlin JMJr. No difference in postoperative pain after arthroscopic versus open rotator cuff repair. Clin Orthop Relat Res 2014;472(09):2759-2765

71 Farner S, Malkani A, Lau E, Day J, Ochoa J, Ong K. Outcomes and cost of care for patients with distal radius fractures. Orthopedics 2014;37(10):e866-e878

72 Gelfman R, Melton LJ III, Yawn BP, Wollan PC, Amadio PC, Stevens JC. Long-term trends in carpal tunnel syndrome. Neurology 2009; 72(01):33-41

73 Nellans KW, Kowalski E, Chung KC. The epidemiology of distal radius fractures. Hand Clin 2012;28(02):113-125
74 Fnais N, Gomes T, Mahoney J, Alissa S, Mamdani M. Temporal trend of carpal tunnel release surgery: a population-based time series analysis. PLoS One 2014;9(05):e97499

75 Hammert WC, Gonzalez R, Elfar JC. Evaluation of patients' perception of safety to drive after outpatient, minimally invasive procedures of the hand. Hand (N Y) 2012;7(04):447 449

76 Acharya AD, Auchincloss JM. Return to functional hand use and work following open carpal tunnel surgery. J Hand Surg $[\mathrm{Br}] 2005$; 30(06):607-610

77 Lewis C, Mauffrey C, Hull P, Brooks S. Knee arthroscopy and driving. Results of a prospective questionnaire survey and review of the literature. Acta Orthop Belg 2011;77(03):336-338 